\title{
Giant Petroclival Primary Intradural Chordoma: Case Report and Systematic Review of the Literature
}

\author{
Fahad AlOtaibi $^{1,2}$ Marie-Christine Guiot ${ }^{3}$ Thierry Muanza ${ }^{4}$ Salvatore Di Maio ${ }^{1}$ \\ ${ }^{1}$ Division of Neurosurgery, Department of Radiation Oncology, McGill \\ University, Jewish General Hospital, Montreal, Quebec, Canada \\ 2 Department of Neurosurgery, National Neuroscience Institute, King \\ Fahad Medical Center, Riyadh, Saudi Arabia \\ ${ }^{3}$ Department of Neuropathology, McGill University, Montreal \\ Neurological Institute, Montreal, Quebec, Canada \\ ${ }^{4}$ Department of Radiation Oncology, McGill University, Jewish General \\ Hospital, Montreal, Quebec, Canada \\ J Neurol Surg Rep 2014;75:e160-e169.

\begin{abstract}
Address for correspondence Salvatore Di Maio, MDCM, FRCS(C), Division of Neurosurgery, McGill University, Jewish General Hospital, Pavilion E, Room 929, 3755 Côte-Sainte-Catherine Road, Montreal, QC H3T 1E2, Canada (e-mail: sdimaio@jgh.mcgill.ca).
\end{abstract}

Background Chordomas are rare, locally aggressive neoplasms thought to arise from notochordal remnants in the axial skeleton. Primary intradural chordomas are considered to be extremely rare. In this article a giant intradural petroclival chordoma is presented, and a synthesis of the available literature is performed to measure overall survival (OS) and recurrence-free survival (RFS) and to identify prognostic factors.

Methods A systematic Medline review yielded 47 patients with purely intradural tumors from 38 publications including 39 chordomas, 8 cases of ecchordosis physaliphora, and 1 case with features of both. The 5-year OS and RFS were calculated based on the Kaplan-Meier method. Risk factors for progression or mortality were analyzed using binomial logistic regression.

Results Maximal tumor diameter varied from 1.5 to $6.0 \mathrm{~cm}$ (mean: $3.2 \mathrm{~cm}$ ). Tumors were located predominantly in the prepontine area (66.7\%). Combined 5-year KaplanMeier OS and RFS were $77 \% \pm 11 \%$ and $74 \% \pm 11 \%$, respectively. Incomplete surgical resection, larger tumor diameter, and an elevated Ki-67 index were statistically more frequent in cases of recurrence and mortality.

Conclusions Based on a systematic literature review, the behavior of primary intradural chordomas may be closer to typical chordomas than was previously thought.

\section{Introduction}

Chordomas are rare locally aggressive neoplasms of notochordal origin, constituting 2 to $4 \%$ of primary bone tumors. ${ }^{1}$ In contrast to ecchordosis physaliphora (EP), which are usually small incidentally discovered rests of tissue within the clivus or retroclival space, cranial base chordomas mostly arise extradurally and produce symptoms secondary to growth and bony destruction. Rare cases of extraosseous intradural chordoma have been reported and generally considered to have a more favorable prognosis relative to typical chordomas. ${ }^{2-4}$ We report a case of a giant intradural chordoma lacking bony involvement. We furthermore performed a systemic review of the literature to (1) assess for clinical, histologic, and radiologic differences between intradural chordoma and EP; (2) summarize overall survival (OS) and recurrence-free survival (RFS) data; and (3) identify risk factors impacting 5-year RFS and OS in patients with intradural chordomas and EP. received

February 12, 2014

accepted

April 9, 2014

published online

June 26, 2014
DOI http://dx.doi.org/

$10.1055 / \mathrm{s}-0034-1378157$.

ISSN 2193-6358. (c) 2014 Georg Thieme Verlag KG Stuttgart · New York
License terms

(1) $\Theta \circledast$ 


\section{Materials and Methods}

The current study is a systematic review of the literature applying the Preferred Reporting Items for Systematic Reviews guidelines. ${ }^{5}$ All studies included were case reports or small primarily retrospective case series.

\section{Search Strategy}

A systematic electronic article search was conducted through Medline between 1974 and 2013, using the Medical Subject Heading terms chordoma, ecchordosis physaliphora, notochord, bone neoplasms, and skull base neoplasms. Titles and abstracts were then reviewed to identify cases of intradural chordomas or ecchordosis physaliphora. A manual search was also conducted from the reference lists of selected articles to identify additional studies. Of these articles, a full-text review was performed by two coauthors independently (F.A. and S.D.), applying inclusion and exclusion criteria to obtain a final group of included studies. Studies were included if (1) they reported patients with histologically confirmed intradural chordomas or ecchordosis physaliphora; (2) patients were symptomatic and/or had large ( $\geq 3 \mathrm{~cm}$ maximal diameter) or growing tumors; and (3) tumors were found to have bony stalk without evidence of bony destruction. Articles were excluded if (1) patients were asymptomatic and/or had small $(<1 \mathrm{~cm}$ maximal diameter) tumors; (2) if the article was an autopsy, nonsurgical, or pure radiologic series; and (3) if the patient was treated in the era before computed tomography (CT) or magnetic resonance imaging (MRI).

\section{Data Collection}

After a final list of articles was assembled, individual patient data were extracted and compiled on to a master database. Patient age, sex, tumor size, location, pathologic diagnosis, presenting symptoms, extent of surgical resection, adjuvant therapy, follow-up duration, recurrence, and mortality were all recorded.

\section{Statistical Analyses}

From the compiled patient database, 5-year overall OS and RFS were calculated using the Kaplan-Meier method. Risk factors for progression or mortality were analyzed using binomial logistic regression. An assessment of risk of bias was not possible for this study. A $p$ value $<0.05$ was considered to be statistically significant. Statistics were performed using IBM SPSS v.21.0 (IBM, Inc, Armonk, New York, United States).

\section{Results}

An initial systematic Medline search yielded 416 publications. After screening based on title and abstract review and applying the previously described inclusion and exclusion criteria, there were 38 publications including 47 patients. The details of each study are tabulated in Appendix A, and subject demographics from the literature cases and ours (48 patients total) are summarized in -Table 1. Patient age ranged from 9 to 76 years (mean: 42.8 years) and maximal tumor diameter varied from 1.5 to $6 \mathrm{~cm}$ (mean: $3.2 \mathrm{~cm}$ ). Tumors were located predominantly in the prepontine (66.7\%) and sellar/suprasellar/hypothalamic (18.8\%) areas, and the postoperative follow-up ranged from 3 weeks to 144 months (mean: 30.2 months). Pathologic diagnosis was reported as chordoma in 39 cases and ecchordosis physaliphora in 8 cases. In one series of two patients in which the distinction of EP versus chordoma was not explicitly made, ${ }^{6}$ the diagnosis was inferred based on the histologic description provided in the manuscript (one EP and one chordoma). In one case, histologic features of both chordoma and EP were reported. ${ }^{7}$ Of 43 of 48 patients for whom extent of surgical resection was reported, 25 had complete or near-complete resection, whereas 18 had subtotal removal. Information regarding adjuvant radiation therapy was available in 41 of 48 cases. Adjuvant radiotherapy was administered in seven cases; all of these patients had undergone subtotal resections. In most cases, radiation therapy was not given (32/41 cases) or given only at recurrence (2/41 cases). None of the cases had bony involvement. In four cases, a bony stalk was observed connecting the intradural tumor to the clivus but without frank bony destruction. In the remaining cases, a bony stalk was absent. Clinical presentation varied between cases but was mainly secondary to brainstem involvement: $52.5 \%$ of patients experienced headaches, cranial nerve palsies were observed in $41.5 \%$, and gait disturbance in $30 \%$. Most of the cases presented with subacute to chronic symptoms, and only a few presented with acute neurologic deterioration related to tumoral hemorrhage. One case of EP presented with fatal diffuse nonaneurysmal subarachnoid hemorrhage, and another chordoma with intratumoral hemorrhage. ${ }^{3,8}$

Survival data were available for 32 of 48 patients. Based on the Kaplan-Meier survival analysis of the compiled available individual patient data, 5 -year RFS was $74 \% \pm 11 \%$, and mean RFS was 112.0 months (95\% confidence interval [CI]: 86.6137.5 months) (-Fig. 1A). The 5-year OS was $77 \% \pm 11 \%$; excluding 30-day surgical mortality, 5-year OS was $87 \% \pm 7 \%$. Mean OS was 115.9 months (95\% CI, 90.7-141.2 months) (-Fig. 1B). The 5-year OS for patients undergoing complete resection was $92 \% \pm 8 \%$, compared with $63 \% \pm 18 \%$ for those with subtotal resection ( $p=0.00004)$. The 5-year RFS for patients undergoing complete resection was $83 \% \pm 15$, compared with $64 \% \pm 15 \%$ for those with subtotal resection $(p=0.00290)$. Patients who developed recurrence had a larger tumor diameter $(4.3 \pm 0.5 \mathrm{~cm}$ versus $3.2 \pm 1.2 \mathrm{~cm}$; $p=0.0390)$ and a more elevated Ki-67 index (6.83 $\pm 1.21 \%$ versus $1.03 \pm 1.84 \% ; p<0.001)$ compared with those who did not ( - Tables 2 and 3). Similarly, patients who died had a larger tumor diameter $(4.8 \pm 0.8 \mathrm{~cm}$ versus $3.2 \pm 1.2 \mathrm{~cm}$; $p=0.039)$ and a more elevated Ki-67 index $(6.83 \pm 1.21 \%$ versus $1.03 \pm 1.84 \% ; p<0.001)$ than those who survived. No other recurrence or survival-related risk factors analyzed were found to be statistically significant.

\section{Case Illustration}

The patient is a 51-year-old right-handed man who works as a janitor. He presented with a 2-year history of balance difficulty and initially vertical diplopia, followed by diplopia in all 
Table 1 Subject demographics

\begin{tabular}{|c|c|}
\hline No. of subjects & 48 (25 males/20 females/3 not specified) \\
\hline Mean age & $42.8 \pm 17.9$ y (range: $9.0-76.0$ y) \\
\hline Follow-up & $30.2 \pm 33.0$ mo (range: $0.75-144.0 \mathrm{mo}$ ) \\
\hline \multicolumn{2}{|l|}{ Tumor location } \\
\hline Prepontine & $32 / 48(66.7 \%)$ \\
\hline Sellar/suprasellar/hypothalamic & $9 / 48(18.8 \%)$ \\
\hline $\begin{array}{l}\text { Other (cerebellar, foramen magnum, tentorial, } \\
\text { pineal, petroclival, disseminated) }\end{array}$ & $7 / 48(14.6 \%)$ \\
\hline Maximal tumor diameter & $3.2 \pm 1.3 \mathrm{~cm}$ (range: $1.5-6.0 \mathrm{~cm}$ ) \\
\hline \multirow[t]{3}{*}{ Reported histology } & Chordoma: 38/48 (79.2\%) \\
\hline & EP: $9 / 48(18.8 \%)$ \\
\hline & Chordoma and EP $1 / 48$ (2.1\%) \\
\hline \multicolumn{2}{|l|}{ Presenting symptoms } \\
\hline Cranial nerve palsy & $17 / 41(41.5 \%)$ \\
\hline Headaches & $21 / 40(52.5 \%)$ \\
\hline Intraventricular hemorrhage & $1 / 40(2.5 \%)$ \\
\hline Gait disturbance & $12 / 40(30.0 \%)$ \\
\hline Tinnitus & $3 / 40(7.5 \%)$ \\
\hline Speech disturbance & $3 / 40(7.5 \%)$ \\
\hline Motor weakness & $7 / 40(17.5 \%)$ \\
\hline Memory disturbance & $6 / 40(15.0 \%)$ \\
\hline Visual signs or symptoms & $9 / 40(22.5 \%)$ \\
\hline Sensory symptoms & $3 / 40(7.5 \%)$ \\
\hline \multicolumn{2}{|l|}{ Adjuvant radiation therapy } \\
\hline Upfront & $7 / 41(17.0 \%)$ \\
\hline At recurrence & $2 / 41(4.9 \%)$ \\
\hline None & $32 / 41(78.0 \%)$ \\
\hline Information not specified & $7 / 48$ \\
\hline
\end{tabular}

Abbreviation: EP, ecchordosis physaliphora.

vectors. He also complained of decreased hearing and facial sensation on the left side. On examination, he had nearcomplete ophthalmoplegia in the left eye, as well as left ptosis and a fixed, dilated pupil. There was $20 \%$ subjective sensation in the left V1-3 dermatomes. His gait was ataxic, and he had psychomotor slowing as well as mild word-finding difficulty. He had diffuse hyperreflexia, and positive Hoffman and Babinski reflexes. There was bilateral upper and lower extremity dysmetria.

His magnetic resonance imaging (MRI) demonstrated a giant left petroclival intradural lesion extended from the jugular foramen caudally and superior to the tentorium to the parasellar space and cavernous sinus (-Fig. 2 ). A head computed tomography (CT) demonstrated a lack of any bony destruction, remodeling, or tumoral involvement. There was severe effacement of the brainstem and partial encasement of the basilar and ipsilateral vertebral arteries. The lesion appeared lobulated, hyperintense on $\mathrm{T} 2$, hypointense on $\mathrm{T} 1$, and there was only mild heterogeneous enhancement. The preoperative differential diagnosis included atypical meningioma, schwannoma, neuroepithelial cyst, and chordoma. A preoperative CT scan did not demonstrate any bony involvement of the tumor.

\section{Operation}

The patient underwent a left-sided posterior transpetrosal approach. Intraoperative monitoring of long tract motor- and sensory-evoked potentials, as well as brainstem auditory evoked responses and cortically evoked facial nerve motorevoked potentials was performed. The presigmoid dura was opened from above the jugular bulb across the superior petrosal sinus and to the temporal lobe. The vein of Labbé was seen coursing posteriorly to drain into the transverse sinus. The tentorium was divided posterior to the course of the trochlear nerve. An expansile mass was seen medial to the trochlear, trigeminal and VII-VIII nerves. It was debulked and 


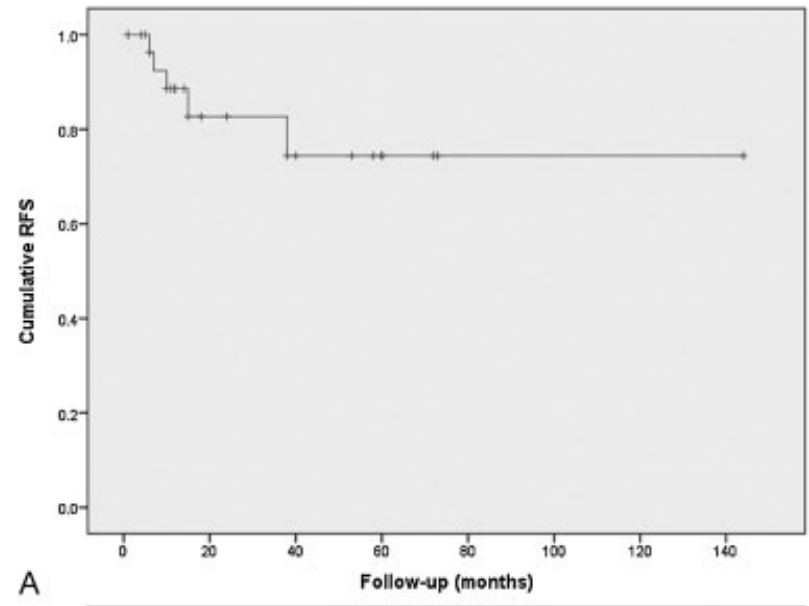

A

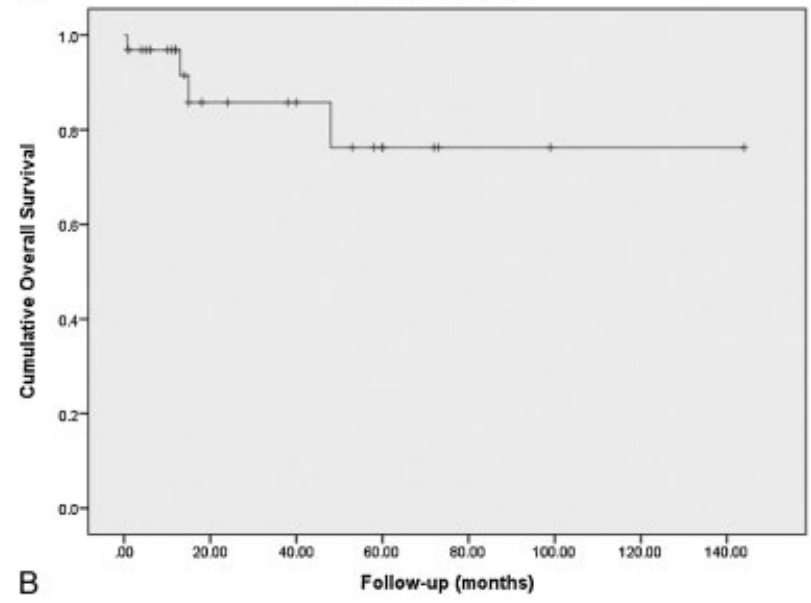

Fig. 1 (A) Kaplan-Meier recurrence-free survival (RFS) curve of 32 of 48 patients with primary intradural chordoma. The 5-year RFS was $74 \% \pm 11 \%$, and mean RFS was 112.0 months ( $95 \%$ confidence interval [CI], 86.6-137.5 months). (B) Kaplan-Meier overall survival (OS) curve of 32 of 48 patients with primary intradural chordoma. The 5-year OS was $77 \% \pm 11 \%$; excluding 30 -day surgical mortality, 5 -year OS was $87 \% \pm 7 \%$. Mean OS was 115.9 months ( $95 \% \mathrm{Cl}, 90.7-141.2$ months).

mobilized without difficulty. Superiorly, the tumor was resected up to the cavernous sinus; however, the visualization offered by the approach was inadequate and a small remnant was believed to have been left behind. Medially, the tumor dissected very well off the brainstem and basilar artery. The tumor was followed into Meckel cave, which was partially unroofed and packed with Surgicel and Tisseel following tumor removal. The remainder of the tumor was removed, and intraoperative monitoring remained pristine throughout the case.

\section{Pathology}

All the histologic sections examined showed the presence of a tumoral proliferation composed of cells with vacuolated cytoplasm and areas resembling cartilage (-Fig. 3). In some areas, the cells formed anastomotic cords floating in a chondroid type of matrix. Cytokeratin immunohistochemistry was strongly positive, and there was focal but definite positivity for both S-100 and brachyury. The Ki-67 index was very low $(<0.5 \%)$, with only a few positive nuclei. Final diagnosis was consistent with chordoma.

\section{Postoperative Course}

Postoperative MRI (- Fig. 2) demonstrated complete resection of the posterior fossa tumor with an expected small remnant within the cavernous sinus. His postoperative course was complicated by a single partial complex seizure on postoperative day 1 , for which antiepileptic medication was not started, and there were no further episodes. He also developed a pseudomeningocele that resolved spontaneously without specific intervention. His ataxia, weakness, psychomotor slowing, ptosis, and diplopia all resolved postoperatively, although clinically he continues to have a trochlear nerve palsy.

At 3 months postoperatively, the patient received fractionated stereotactic radiotherapy (fSRT) with an intensity-modulated radiotherapy RAPID Arc system (Varian Medical Systems, Palo Alto, California, United States) using MRI fusion. A total dose of $52 \mathrm{~Gy}$ was delivered in 28 fractions. His last follow-up MRI at 12 months from surgery demonstrated no recurrence of the tumor.

\section{Discussion}

Luschka first described his finding of pathologic ectopic notochordal tissue at the posterior clivus in $1856 .{ }^{9}$ In 1857 , Virchow gave the first microscopic description and termed the lesion ecchondrosis physaliphora, believing it to be a process affecting the cartilage of the spheno-occipital

Table 2 Risk factors associated with recurrence in 32/48 patients with intradural chordoma or ecchordosis physaliphora

\begin{tabular}{|l|l|l|l|}
\hline & Recurrence $(\boldsymbol{n}=\mathbf{5})$ & No recurrence $(\boldsymbol{n}=\mathbf{2 7})$ & $\boldsymbol{p}$ value \\
\hline Maximal diameter, cm & $4.3 \pm 0.5$ & $3.1 \pm 1.3$ & 0.010 \\
\hline Age, y & $46.0 \pm 16.4$ & $38.2 \pm 19.0$ & 0.381 \\
\hline Sex & 1 male/4 females & 17 males/8 females & 0.130 \\
\hline Enhancement & 5 yes/0 no & 18 yes/7 no & 0.355 \\
\hline Pathology & 5 chordoma/0 EP & 22 chordoma $/ 5$ EP & 0.284 \\
\hline Bony stalk & 0 yes $/ 5$ no & 3 yes/24 no & 0.424 \\
\hline Ki-67, \% & $5.12 \pm 3.56$ & $1.08 \% \pm 1.88$ & 0.004 \\
\hline
\end{tabular}

Abbreviation: EP, ecchordosis physaliphora. 
Table 3 Risk factors associated with overall survival in 32/48 patients with intradural chordoma or ecchordosis physaliphora

\begin{tabular}{|l|l|l|l|}
\hline & Nonsurviving $(\boldsymbol{n}=\mathbf{4})$ & Surviving $(\boldsymbol{n}=\mathbf{2 8})$ & $\boldsymbol{p}$ value \\
\hline Maximal diameter, $\mathrm{cm}$ & $4.8 \pm 0.8$ & $3.2 \pm 1.2$ & 0.039 \\
\hline Age, $\mathrm{y}$ & $39.8 \pm 0.9 \mathrm{~cm}$ & $39.5 \pm 19.6$ & 0.980 \\
\hline Sex & 1 male/3 females & 16 males/10 females & 0.170 \\
\hline Enhancement & 4 yes/0 no & 21 yes/7 no & 0.467 \\
\hline Pathology & 4 chordoma/0 EP & 26 chordoma/2 EP & 0.358 \\
\hline Bony stalk & 0 yes/5 no & 3 yes/24 no & 0.492 \\
\hline Ki-67, \% & $6.83 \pm 1.21$ & $<.03 \pm 1.84$ & $<.001$ \\
\hline
\end{tabular}

Abbreviation: EP, ecchordosis physaliphora.

synchondrosis. ${ }^{10}$ One year later, Müller correctly proposed a notochordal origin, ${ }^{11}$ and in 1894 , Ribbert and Steiger coined the term ecchordosis to reflect a presumed notochordal origin of these lesions. ${ }^{12} \mathrm{EP}$ is considered to be an ectopic notochordal remnant lacking internal proliferative potential. ${ }^{4}$ Whether EP is the precursor of skull base chordoma remains controversial. $^{13-15}$ Furthermore, debate persists regarding whether large symptomatic EP is truly distinct from intradural chordoma, or whether they are terms describing the same pathologic entity. 2,3,7

Wolfe and Scheithauer et $\mathrm{al}^{6}$ proposed the term intradural chordoma should be for all lesions, including EP, whereas Rodríguez et $\mathrm{al}^{7}$ argued that all instances of symptomatic, intradural, extraosseous physaliphora cell growth should be classified as giant or symptomatic EP so long as the existence of an intradural chordoma is not definitely proved. Histologically, EP and intradural chor- doma display many similarities including the presence of typical "vacuolated cells" and positive staining for Brachyury and Galectin-3. Pragmatically speaking, in many cases the pathologic diagnosis is influenced and supported by the clinical picture and radiologic findings. Specific histologic differences have been proposed including a smaller cell number and absence of extracellular mucuslike matrix or necrotic cells in EP. ${ }^{13-15}$ Wang et $\mathrm{al}^{16}$ described the volume of EPs to be characteristically less than intradural chordomas, with the largest reported diameter $<2 \mathrm{~cm}$; however, there are literature instances of so-called EP with diameters of $4 \mathrm{~cm},{ }^{17} 3 \mathrm{~cm},{ }^{7}$ and $3 \mathrm{~cm} .{ }^{18}$ Other distinguishing features proposed include the presence of clinical symptoms including those related to brainstem compression and/or cranial nerves palsies in true chordomas, a low Ki-67 index in EP, ${ }^{19}$ as well as contrast enhancement in true chordomas versus lack of

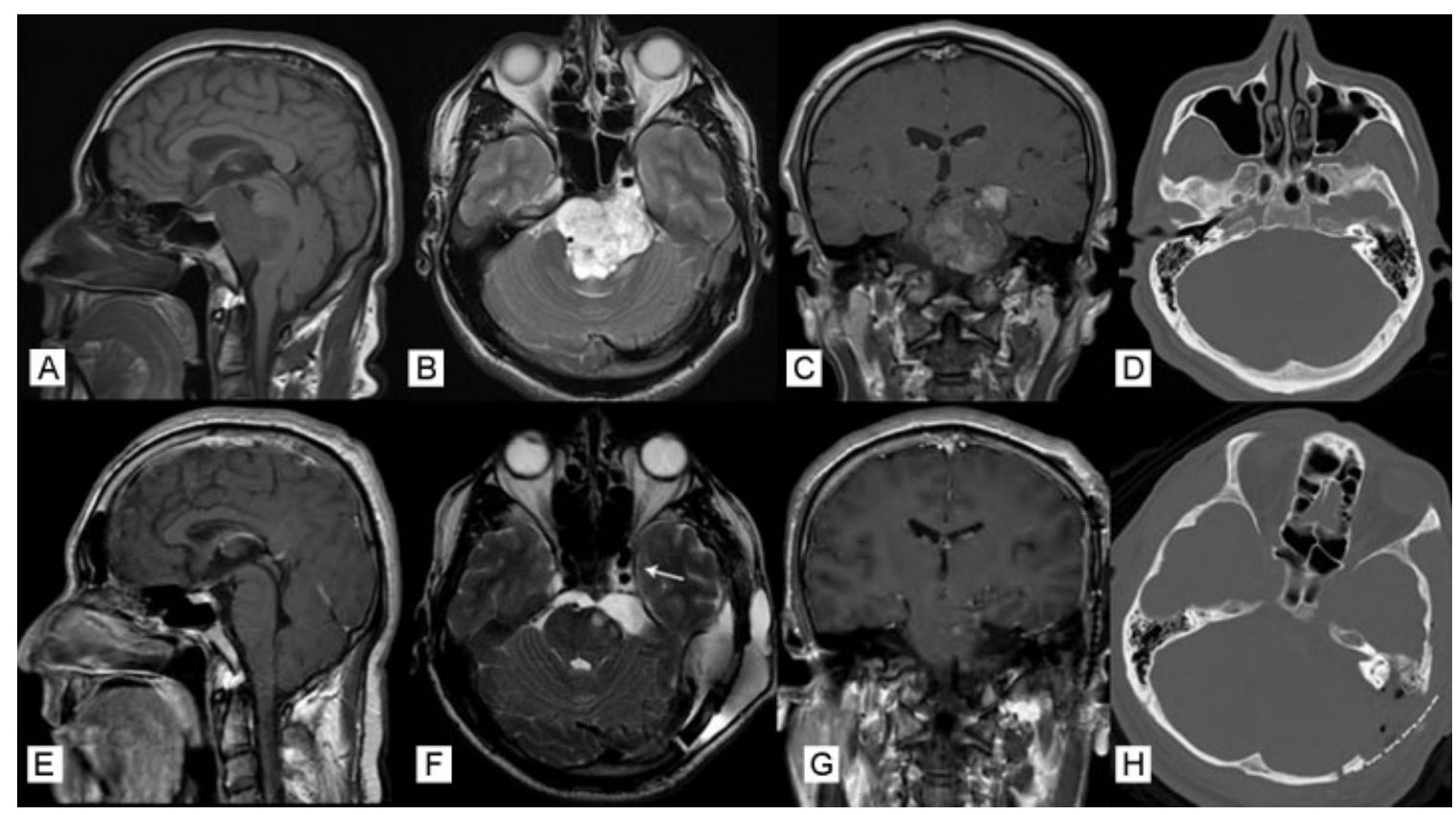

Fig. 2 Preoperative (A) sagittal T1, (B) axial T2, and (C) coronal T1 magnetic resonance imaging (MRI) with gadolinium demonstrating a large left petroclival intradural chordoma. (D) Preoperative computed tomography (CT) did not demonstrate any bony involvement. (E-G) Postoperative MRI showing near-complete resection with a likely small residual in the left cavernous sinus ( $F$, arrow). (H) Postoperative CT showing skeletonization of semicircular canals. Preoperative CT did not disclose any bony involvement. 


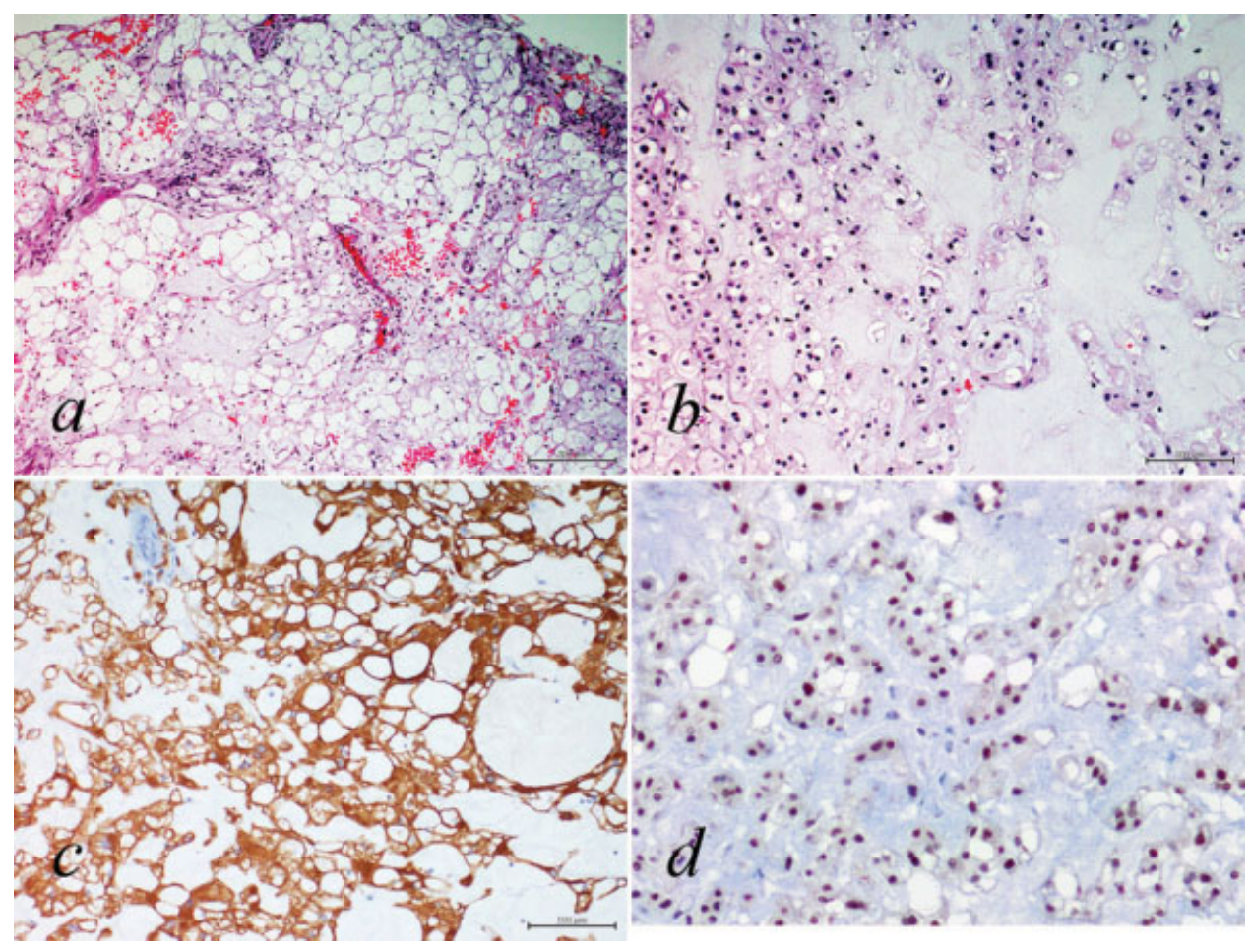

Fig. 3 Hematoxylin and eosin stained sections showing a tumoral proliferation composed of cells with (A) vacuolated cytoplasm and (B) areas resembling cartilage. (C) Cytokeratin immunohistochemistry was strongly positive. (D) There was nuclear positivity for brachyury. Final pathology was consistent with chordoma.

enhancement in EP. ${ }^{20}$ The presence of a bony stalk was reported in several cases; however, we did not find it to be a distinguishing feature of EP versus chordoma, nor did it appear to affect prognosis.

Based on prior case reports and small series, intradural chordomas have generally been considered to have a more favorable prognosis and a different biologic behavior relative to typical cranial base chordomas. ${ }^{8}$ The data from our systematic review suggest that both 5-year RFS and OS appear to be comparable with typical chordomas, particularly following a complete surgical resection. In a recent meta-analysis of cranial base chordomas, ${ }^{21}$ 5-year RFS was $87 \%$ in patients with complete resection compared with $50 \%$ in patients with incomplete resection, and 5-year OS was 95\% with complete resection versus $71 \%$ without. This is similar to our study, in which 5-year RFS for patients undergoing complete resection was $83 \% \pm 15$, compared with $64 \% \pm 15 \%$ for those with subtotal resection, and in which 5 -year OS was $92 \% \pm 8 \%$ with complete resection, compared with $63 \% \pm 18 \%$ with incomplete resection $(p<0.001)$. Thus although a gross total resection may be more feasible for true intradural chordomas, their biologic behavior may nevertheless be similar to classic skull base chordomas and is reflected by similar survival of both subtypes after complete and incomplete resections.

The cellular and molecular mechanisms by which chordomas effectuate bony invasion and overall aggressiveness remain poorly understood, and in light of the relative rarity of intradural chordomas and EP, differentiating features are as yet lacking. Proteases may be implicated in bony destruction in chordomas. Matrix metalloproteinases ${ }^{22}$ and cathepsin $\mathrm{K}^{22,23}$ have been investigated as potential mediators; their increased expression appear related to worse prognosis. Adhesion proteins may also mediate tumor invasiveness in chordomas. Upregulation of $\mathrm{N}$-cadherin and downregulation of E-cadherin may be correlated with worse clinical behavior of some chordomas. ${ }^{24}$ Upregulation of specific proto-oncogenes have also been evaluated, including c-MET and hepatocyte growth factor expression. $^{25}$ Fascin overexpression was also correlated with increased chordoma invasiveness and dural penetration, implicating increased cell motility as a potential mechanism. ${ }^{26}$ Increased telomerase activity also appears to correlate with chordoma recurrence and possible aggressiveness. ${ }^{27}$ The cellular proliferative potential, as measured by the Ki-67 staining index, has been reported to distinguish EP from chordoma. ${ }^{14,15}$ Reported cases of EP typically have a Ki-67 index $<1 \%$, whereas in chordoma it is $>2 \%$. Accordingly, all the cases included in our systematic review demonstrated a Ki-67 index $<2 \%$ in EP.

Our study is subject to several important limitations. All included studies are of a retrospective nature composed primarily of case reports and a few small case series, and they subject our meta-analysis to potential publication bias. Heterogeneity in the compiled cohort was observed due to local differences in the use of adjuvant radiation therapy, and often unclear justification for the pathologic distinction between EP and true chordoma. The histologic distinguishing features between chordoma and EP are unclear; there is heterogeneity in the pathologic distinction of intradural 
cases included in our literature synthesis. Finally, the overall small population limits statistical power.

\section{Conclusion}

Intradural cranial base chordomas are extremely rare. There is lack of uniform agreement regarding the distinguishing features of chordoma and ecchordosis physaliphora, particularly for large symptomatic tumors. Based on our metaanalysis, the clinical behavior of intradural chordomas may be closer to typical cranial base chordomas than was previously recognized. This finding may influence clinical management, particularly the use of adjuvant radiation therapy as in our case illustration.

\section{Disclosure}

The authors report no conflict of interest concerning the materials or methods used in this study or the findings specified in this article.

\section{References}

1 Warnick RE, Raisanen J, Kaczmar T Jr, Davis RL, Prados MD. Intradural chordoma of the tentorium cerebelli. Case report. J Neurosurg 1991;74(3):508-511

2 Yuhi F, Asakura T, Tomosugi T, Kusumoto K, Awa H, Uetsuhara K. A case of clival chordoma without bone destruction. [in Japanese]. No Shinkei Geka 1986;14(4):547-552

3 Uda T, Ohata K, Takami T, Hara M. An intradural skull base chordoma presenting with acute intratumoral hemorrhage. Neurol India 2006;54(3):306-307

4 Masui K, Kawai S, Yonezawa T, Fujimoto K, Nishi N. Intradural retroclival chordoma without bone involvement-case report. Neurol Med Chir (Tokyo) 2006;46(11):552-555

5 Moher D, Liberati A, Tetzlaff J, Altman DG; PRISMA Group. Preferred reporting items for systematic reviews and meta-analyses: the PRISMA statement. BMJ 2009;339:b2535

6 Wolfe JT III, Scheithauer BW. "Intradural chordoma" or "giant ecchordosis physaliphora"? Report of two cases. Clin Neuropathol 1987;6(3):98-103

7 Rodríguez L, Colina J, López J, Molina O, Cardozo J. Intradural prepontine growth: giant ecchordosis physaliphora or extraosseous chordoma? Neuropathology 1999;19:336-340

8 Fracasso T, Brinkmann B, Paulus W. Sudden death due to subarachnoid bleeding from ecchordosis physaliphora. Int J Legal Med 2008;122(3):225-227

9 Luschka H. Die altersveränderungen der Zwischenwirbelknorpel. Virchows Arch 1856;9:311-327

10 Virchow RLK. Untersuchungen über die Entwickelung des Schädelgrundes im gesunden und krankhaften zustand: und über den einfluss derselben auf Schädelform, Gesichtsbildung und Gehirnbau. Berlin, Germany: Reimer; 1857

11 Müller H. Ueber das Vorkommen von Resten der Chorda dorsalis bei Menschen nach der Geburt und über ihr Verhältniss zu den Gallertgeschwülsten am Clivus. Ztschr F Rat Med 1858; 2:202-229

12 Ribbert H, Steiner H. Uber die Ecchondrosis physalifora sphenooccipitalis. Zentralbl Allg Pathol Anat 1894;5:457-461

13 Mathews W, Wilson CB. Ectopic intrasellar chordoma. Case report. J Neurosurg 1974;40(2):260-263

14 Mapstone TB, Kaufman B, Ratcheson RA. Intradural chordoma without bone involvement: nuclear magnetic resonance (NMR) appearance. Case report. J Neurosurg 1983;59(3):535-537
15 Bergmann M, Abdalla Y, Neubauer U, Schildhaus HU, ProbstCousin S. Primary intradural chordoma: report on three cases and review of the literature. Clin Neuropathol 2010;29(3): 169-176

16 Wang L, Wu Z, Tian K, Li G, Zhang J. Clinical and pathological features of intradural retroclival chordoma. World Neurosurg 2013; February 13 (Epub ahead of print)

17 Takeyama J, Hayashi T, Shirane R. Notochordal remnant-derived mass: ecchordosis physaliphora or chordoma? Pathology 2006; 38(6):599-600

18 Ling SS, Sader C, Robbins P, Rajan GP. A case of giant ecchordosis physaliphora: a case report and literature review. Otol Neurotol 2007;28(7):931-933

19 Amer HZ, Hameed M. Intraosseous benign notochordal cell tumor. Arch Pathol Lab Med 2010;134(2):283-288

20 Mehnert F, Beschorner R, Küker W, Hahn U, Nägele T. Retroclival ecchordosis physaliphora: MR imaging and review of the literature. AJNR Am J Neuroradiol 2004;25(10):1851-1855

21 Di Maio S, Temkin N, Ramanathan D, Sekhar LN. Current comprehensive management of cranial base chordomas: 10-year metaanalysis of observational studies. J Neurosurg 2011;115(6): 1094-1105

22 Naka T, Kuester D, Boltze C, et al. Expression of matrix metalloproteinases-1, -2 , and -9 ; tissue inhibitors of matrix metalloproteinases-1 and -2; cathepsin B; urokinase plasminogen activator; and plasminogen activator inhibitor, type I in skull base chordoma. Hum Pathol 2008;39(2):217-223

23 Haeckel C, Krueger S, Kuester D, et al. Expression of cathepsin K in chordoma. Hum Pathol 2000;31(7):834-840

24 Triana A, Sen C, Wolfe D, Hazan R. Cadherins and catenins in clival chordomas: correlation of expression with tumor aggressiveness. Am J Surg Pathol 2005;29(11):1422-1434

25 Naka T, Kuester D, Boltze C, et al. Expression of hepatocyte growth factor and c-MET in skull base chordoma. Cancer 2008;112(1): 104-110

26 Gao Z, Zhang Q, Kong F, et al. Fascin expression in skull base chordoma: correlation with tumor recurrence and dura erosion. Med Oncol 2012;29(4):2438-2444

27 Pallini R, Maira G, Pierconti F, et al. Chordoma of the skull base: predictors of tumor recurrence. J Neurosurg 2003;98(4):812-822

28 Stam FC, Kamphorst W. Ecchordosis physaliphora as a cause of fatal pontine hemorrhage. Eur Neurol 1982;21(2):90-93

29 Vaquero J, Martinez R, Rossi E, Bravo G. Chordoma. Neurosurgery 1983;13(6):737-738

30 Katayama Y, Tsubokawa T, Hirasawa T, Takahata T, Nemoto N Intradural extraosseous chordoma in the foramen magnum region. Case report. J Neurosurg 1991;75(6):976-979

31 Hardie RC. Magnetic resonance appearance of a rare intradural chordoma. Wis Med J 1992;91(11):627-628

32 Commins D, Baran GA, Molleston M, Vollmer D. Hypothalamic chordoma. Case report. J Neurosurg 1994;81(1):130-132

33 Tashiro T, Fukuda T, Inoue Y, et al. Intradural chordoma: case report and review of the literature. Neuroradiology 1994;36(4): 313-315

34 Wanibuchi M, Uede T, Ishiguro M, Tatewaki K, Kurokawa Y, Yoshida Y. A case of suprasellar intradural chordoma. [in Japanese]. No Shinkei Geka 1994;22(3):269-272

35 Akimoto J, Takeda H, Hashimoto T, Haraoka J, Ito H. A surgical case of ecchordosis physaliphora. [in Japanese]. No Shinkei Geka 1996; 24(11):1021-1025

36 Nishigaya K, Kaneko M, Ohashi Y, Nukui H. Intradural retroclival chordoma without bone involvement: no tumor regrowth 5 years after operation. Case report. J Neurosurg 1998;88(4): 764-768

37 Toda H, Kondo A, Iwasaki K. Neuroradiological characteristics of ecchordosis physaliphora. Case report and review of the literature. J Neurosurg 1998;89(5):830-834 
38 Korinth M, Schönrock L, Mayfrank L, Gilsbach JM. Primary intradural pontocerebellar chordoma metastasizing in the subarachnoid spinal canal. Zentralbl Neurochir 1999;60(3):146-150

39 Danilewicz B, Danilewicz M, Czepko R, Stachura K. Intradural clivus chordoma: surgical treatment with no tumor regrowth 12 years after surgery. [in Polish]. Przegl Lek 2000;57(3): $178-180$

40 Cha ST, Jarrahy R, Yong WH, Eby T, Shahinian HK. A rare symptomatic presentation of ecchordosis physaliphora and unique endoscope-assisted surgical management. Minim Invasive Neurosurg 2002;45(1):36-40

41 Steenberghs J, Kiekens C, Menten J, Monstrey J. Intradural chordoma without bone involvement. Case report and review of the literature. J Neurosurg 2002;97(1, Suppl):94-97

42 Dow GR, Robson DK, Jaspan T, Punt JA. Intradural cerebellar chordoma in a child: a case report and review of the literature. Childs Nerv Syst 2003;19(3):188-191

43 Roberti F, Sekhar LN, Jones RV, Wright DC. Intradural cranial chordoma: a rare presentation of an uncommon tumor. Surgical experience and review of the literature. J Neurosurg 2007;106(2): 270-274

44 Chang SW, Gore PA, Nakaji P, Rekate HL. Juvenile intradural chordoma: case report. Neurosurgery 2008;62(2):E525-E526; discussion E527
45 Alkan O, Yildirim T, Kizilkiliç O, Tan M, Cekinmez M. A case of ecchordosis physaliphora presenting with an intratumoral hemorrhage. Turk Neurosurg 2009;19(3):293-296

46 Choo YS, Joo SW, Noh SJ, Lee SI. Intradural retroclival chordoma. J Korean Neurosurg Soc 2009;46(2):152-155

47 Ciarpaglini R, Pasquini E, Mazzatenta D, Ambrosini-Spaltro A, Sciarretta V, Frank G. Intradural clival chordoma and ecchordosis physaliphora: a challenging differential diagnosis: case report. Neurosurgery 2009;64(2):E387-E388; discussion E388

48 Bhat DI, Yasha M, Rojin A, Sampath S, Shankar SK. Intradural clival chordoma: a rare pathological entity. J Neurooncol 2010;96(2): 287-290

49 Ito E, Saito K, Nagatani T, et al. Intradural cranial chordoma. World Neurosurg 2010;73(3):194-197; discussion e31

50 Jiagang L, Yanhui L, Xueying S, Qing M. Intradural suprasellar chondroid chordoma. J Clin Neurosci 2010;17(3):402-403

51 Figueiredo EG, Tavares WM, Welling L, Rosemberg S, Teixeira MJ. Ectopic pineal chordoma. Surg Neurol Int 2011;2:145

52 Anderson S, Sato Y, Kirby P, Buatti JM, Menezes A. Disseminated subarachnoid chordoma: long-term favorable follow-up of a pediatric patient. Pediatr Radiol 2012;42(7):878-880

53 Kim SK, Kim YH, Park CK, Kim MA, Park SH. Intracranial intradural chordoma presenting with intraventricular hemorrhage. Clin Neurol Neurosurg 2012;114(8):1189-1192 


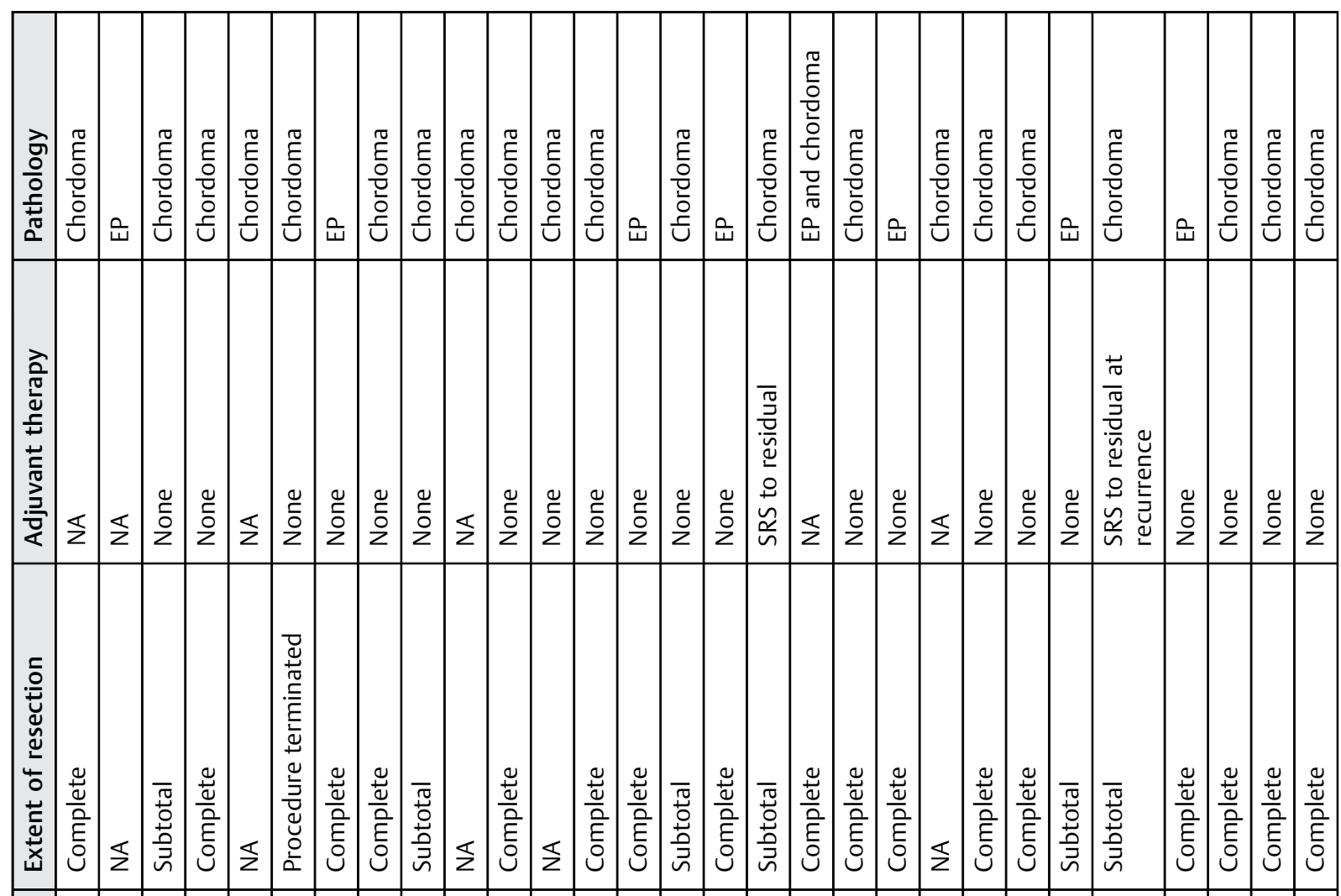

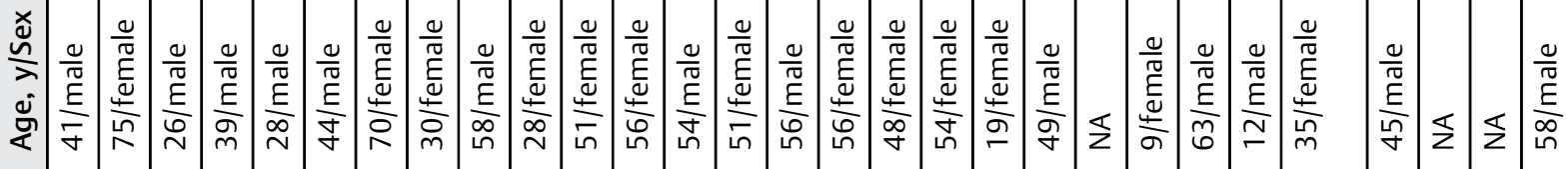

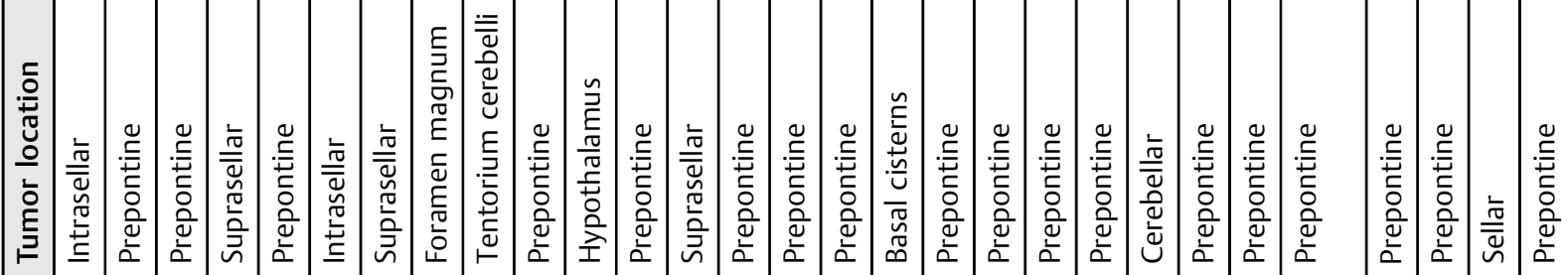

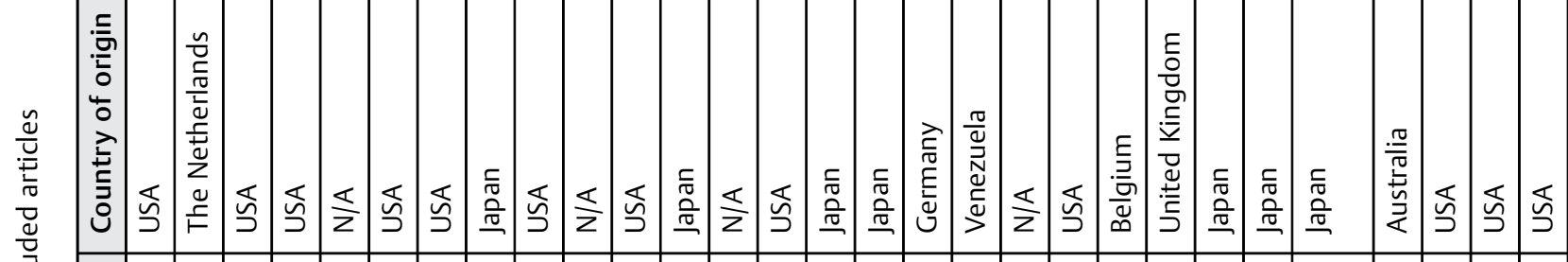

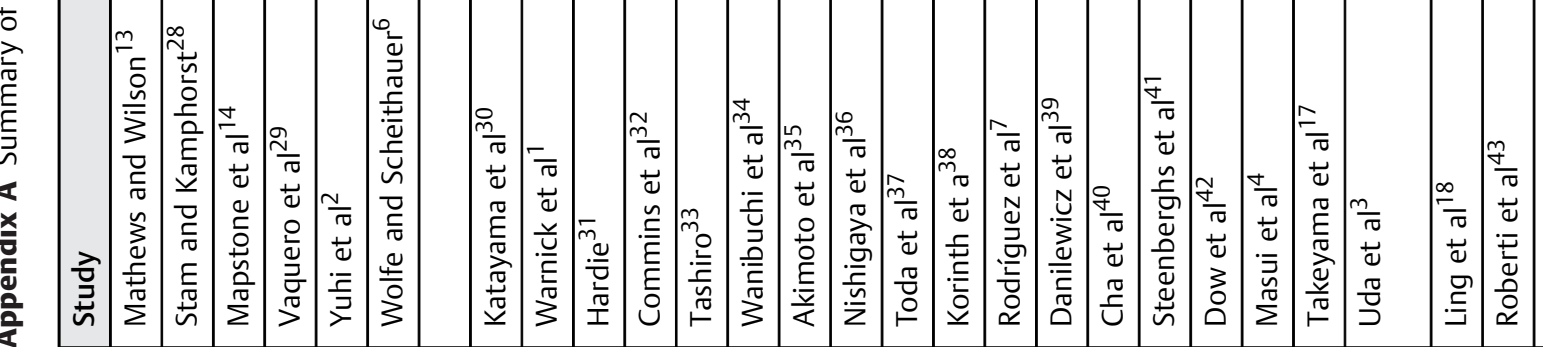



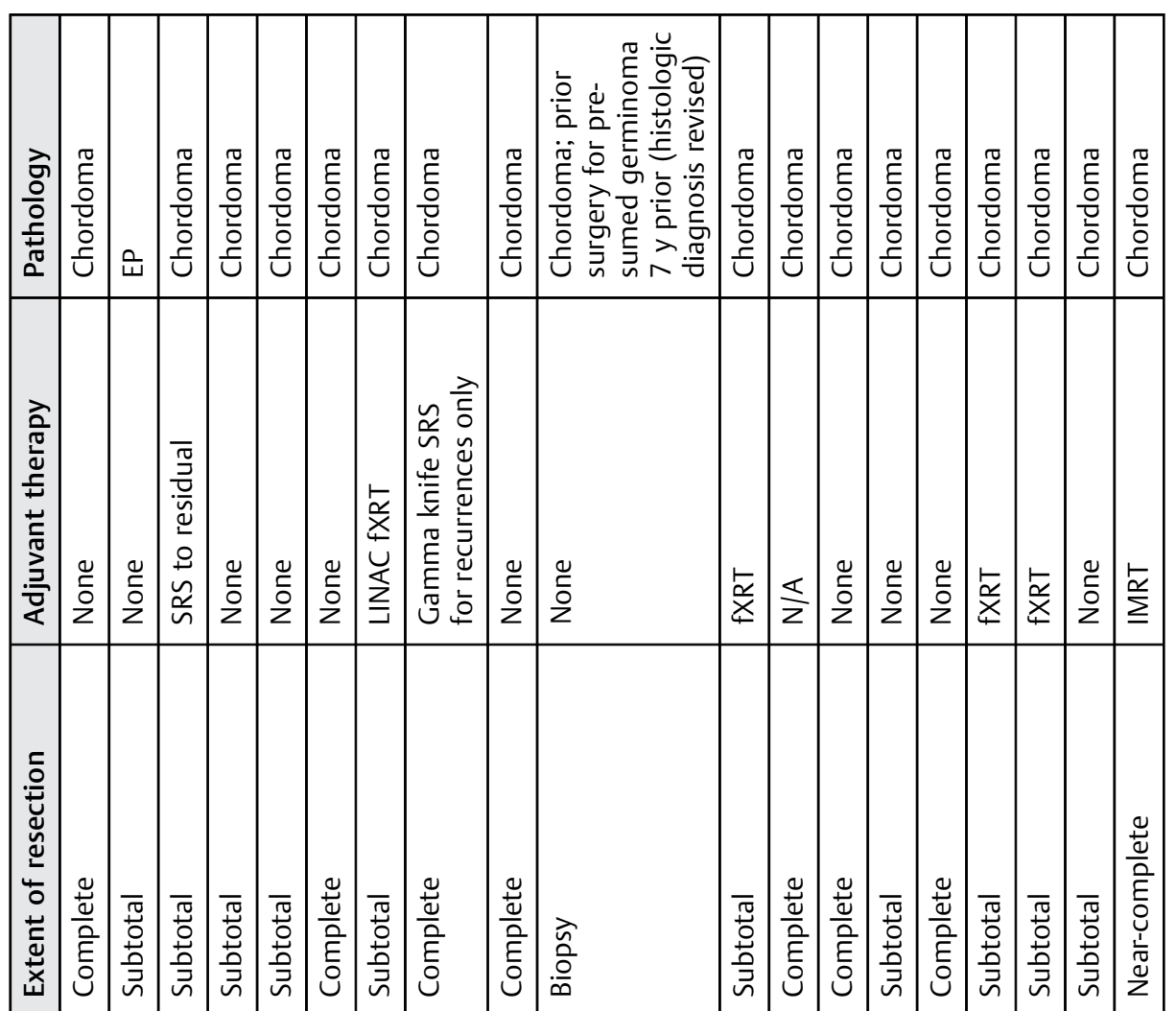

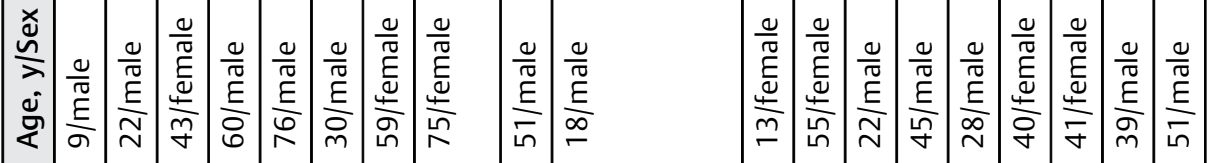

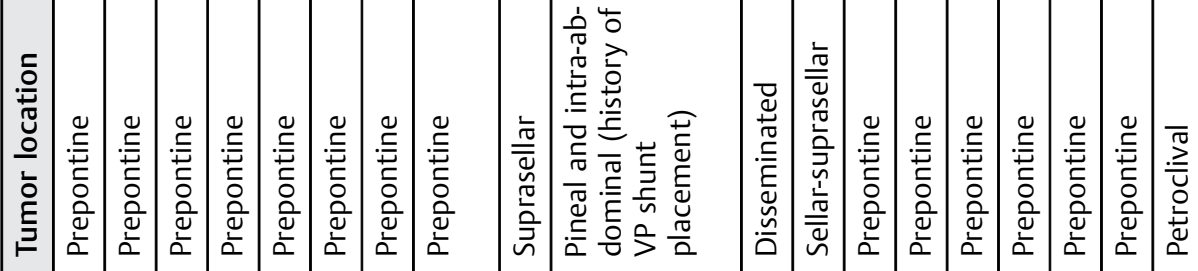

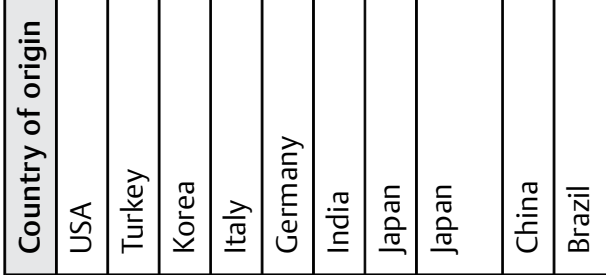

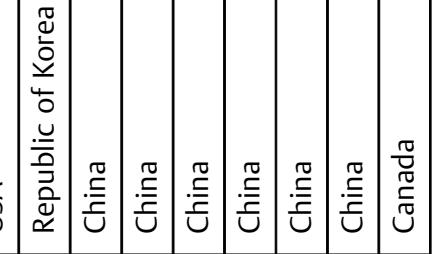

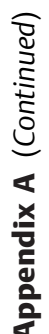

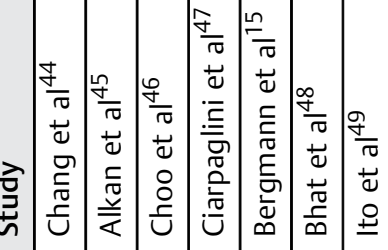

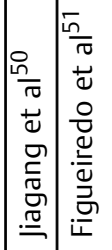

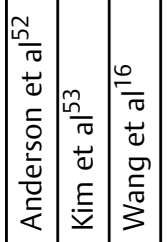

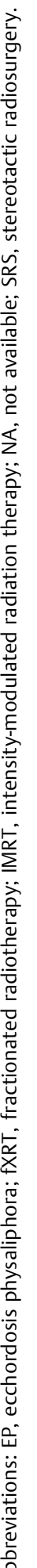

